\title{
Improving Orthopedic Care Delivery Through Digital Engagement
}

Lisa Biernat ${ }^{1}$, RN; Carly E Milliren ${ }^{2}$, MPH; Jon Rauen ${ }^{1}$, MBA; Bill Lindsay ${ }^{3}$, BA; Betsy Weaver ${ }^{3}$, EdD; Todd Smith ${ }^{1}$, MD

${ }^{1}$ HealthEast/Fairview, Woodbury, MN, United States

${ }^{2}$ Center for Applied Pediatric Quality Analytics, Boston Children's Hospital, Boston, MA, United States

${ }^{3}$ UbiCare, Boston, MA, United States

Corresponding Author:

Bill Lindsay, BA

UbiCare

284 Amory Street G-101

Boston, MA, 02130

United States

Phone: 5248861

Email: bill.lindsay@ubicare.com

\section{Abstract}

Background: Patient activation has been hypothesized to improve medical and surgical outcomes by increasing patient involvement in the care plan. We tested this hypothesis by utilizing a patient activation tool in a population of adults having total hip or total knee replacement. We hypothesized that patient activation would be associated with increased discharge to home as opposed to a skilled nursing facility, reduced hospital length of stay, decreased inpatient readmissions, and decreased emergency department (ED) visits.

Objective: Using an email patient activation tool, we sought to increase patients' involvement in their care before and after total joint replacement. Outcomes examined included day of surgery cancellation, length of hospital stay, discharge to home vs discharge to a skilled nursing facility, any ED visit within 30 days of discharge, and any inpatient readmission within 30 days of discharge

Methods: This was a quasi-experimental design comparing Jan-Jun 2017 to Jan-Jun 2018. We instituted an email patient activation tool for all patients with total knee or total hip replacement surgery beginning in January 2018. This tool was integrated with the electronic medical record system during the six month study period and patients could opt out at anytime if they desired. The tool was designed to prepare patients both educationally and emotionally for their operation with multiple easy-to-read emails starting from the time they were scheduled for surgery through six months postop. Percent of emails opened and clicked were used as measures of engagement for the intervention participants.

Results: Of the 2,027 TJR patients included, 720 were hip patients and 1,307 were knee patients. Pre- and postintervention groups were similar in gender and age. For hip replacement patients, length of stay was nearly $1 / 4$ day lower in the postintervention group $(\beta=-0.23 ; P=.001)$ after adjusting for gender, age and insurance; ED visits were lower among the postintervention group $(\mathrm{OR}=0.45 ; P=.05)$ after adjusting for gender, age and insurance; and postintervention patients were less likely to have day of surgery cancellation, any revisit (ED or readmission), and were more likely to be discharged home. However, these associations did not reach statistical significance.

Conclusions: Among patients who received the intervention, higher engagement was significantly associated with positive changes in almost all outcomes. Use of the digital patient activation tool demonstrated significant savings in length of stay and reduced ED visits among hip replacement patients. Although just under 50\% of patients in the intervention group were enrolled to use the tool, these findings were still significant even when non-participants were included in the postintervention group.

(iproc 2019;5(1):e16305) doi: $\underline{10.2196 / 16305}$

\section{KEYWORDS}

mobile technology; patient activation; patient education; digital engagement 
Edited by J Brown; this is a non-peer-reviewed article. Submitted 17.09.19; accepted 18.09.19; published 02.10.19.

Please cite as:

Biernat L, Milliren CE, Rauen J, Lindsay B, Weaver B, Smith T

Improving Orthopedic Care Delivery Through Digital Engagement

iproc 2019;5(1):e16305

URL: http://www.iproc.org/2019/1/e16305/

doi: $\underline{10.2196 / 16305}$

PMID:

CLisa Biernat, Carly E. Milliren, Jon Rauen, Bill Lindsay, Betsy Weaver, Todd Smith. Originally published in Iproceedings (http://www.iproc.org), 02.10.2019 This is an open-access article distributed under the terms of the Creative Commons Attribution License (https://creativecommons.org/licenses/by/4.0/), which permits unrestricted use, distribution, and reproduction in any medium, provided the original work, first published in Iproceedings, is properly cited. The complete bibliographic information, a link to the original publication on http://www.iproc.org/, as well as this copyright and license information must be included. 